\title{
Genetic Diversity of Hippophae rhamnoides Populations at Varying Altitudes in the Wolong Natural Reserve of China as Revealed by ISSR Markers
}

\author{
By G. Chen ${ }^{1), 2)}$, Y. WAnG ${ }^{1), 2)}$, C. ZHAO ${ }^{1), 2)}$, H. KorPelainen ${ }^{3)}$ and C. Li ${ }^{1), *}$
}

(Received $14^{\text {th }}$ September 2006)

\begin{abstract}
Hippophae rhamnoides L., a dioecious and deciduous shrub species, occupies a wide range of habitats in the Wolong Nature Reserve, Southwest China. Our present study investigated the pattern of genetic variation and differentiation among five natural populations of $H$. rhamnoides, occurring along an altitudinal gradient that varied from 1,800 to $3,400 \mathrm{~m}$ above sea level in the Wolong Natural Reserve, by using ISSR markers. Based on fingerprinting patterns generated by fifteen primers, high levels of genetic variation were present within populations and subpopulations. Substantial genetic divergence was observed among populations, and also among female and male subpopulations, the $G_{\mathrm{ST}}$ values equaling $0.182,0.222$, and 0.238 , respectively. Such considerable divergence present among populations and subpopulations may be caused by complex topography which effectively restricts gene flow, and by variable climatic conditions at different altitudes which may cause varying selective pressures. A significantly positive correlation between genetic and altitudinal distances was detected for the five populations and female subpopulations of $H$. rhamnoides. The cluster analysis including all populations or male subpopulations resulted in three altitude groups. Our results suggest that altitudinal gradients may be the prime cause affecting the genetic variation pattern of different populations and subpopulations in $H$. rhamnoides in the Wolong Nature Reserve, Southwest China.
\end{abstract}

Key words: Altitudinal gradients, Genetic variation, Hippophae rhamnoides, ISSR markers, Sex-specific genetic differentiation.

\section{Introduction}

Hippophae rhamnoides L. is a dioecious, wind-pollinated woody plant which mainly grows on sandy soils by sea shores or along river beds (BARTISH et al., 1999). As one of the Frankia-non-leguminous nitrogen-fixing plant species, $H$. rhamnoides is not only a pioneer plant species in its natural ecosystems but also an exploitable species for several purposes, including medicine, wood, fuel wood, fodder and honey (Lu, 1992). Nowadays, $H$. rhamnoides is widely cultivated as a berry crop in China, Russia, Central Asia and Europe (Lu, 1992).

1) Chengdu Institute of Biology, Chinese Academy of Sciences, P. O. Box 416, Chengdu 610041, China.

2) Graduate School of the Chinese Academy of Sciences, Beijing 100039, China.

3) Department of Applied Biology, P.O. Box 27, FI-00014 University of Helsinki, Finland.

*) Correspondence address: ChUnYANG Li, Chengdu Institute of Biology, Chinese Academy of Sciences, P. O. Box 416, Chengdu 610041, China. Tel. +86-28-85221347, Fax +86-28-85222753. Email: licy@cib.ac.cn
$H$. rhamnoides has a wide distribution in Southwest China. Its occurrence in a large range of habitats across different altitudes, although mainly restricted to sunny, south-facing slopes, implies wide adaptation to different environments (LU, 1992; WU and RAVEN, 1994). $H$. rhamnoides plays an important role in preventing soil erosion and soil water loss, and in regulating microclimate, as well as in retaining ecological stability in the region (LU, 1992).

With the advent of molecular markers, isozyme and RAPD (randomly amplified polymorphic DNA) markers have been extensively used in investigations aiming to reveal the level and apportionment of genetic diversity, genetic relationships among species or subspecies, and sex identification of $H$. rhamnoides (PERSSON and NyBom, 1998; BARTish, 2000; RUAN et al., 2004). Among DNA-based molecular markers, compared to RAPDs, ISSRs (inter-simple sequence repeats) have an advantage of having longer primers which require more stringent annealing temperatures, further resulting in more reliable amplification patterns. Therefore, ISSRs have been widely used to detect polymorphisms, analyze phylogenetic relationships, evaluate variation within and among natural populations of many species, identify cultivars, and to distinguish wild and cultivated species (Wolfe and Liston, 1998; CAMACHO and Liston, 2001; NAN et al., 2003).

Since elevation is a complex factor, especially in mountain regions, which produce heterogeneous environmental conditions, such as rapidly changing climate conditions, rugged topography and a complex pattern of vegetation. Furthermore, such variable conditions are likely to markedly affect the genetic variation pattern of a plant species (REHFELDT, 1994; SÁENZ-ROMERO et al., 2003; SÁenz-Romero et al., 2006). Genetic differentiation between populations along altitudinal gradients has been observed in several plant species as a result of rapid, elevation-related changes in environmental conditions (NEvo et al., 1983; FAHIMA et al., 1999; ETTL and Peterson, 2001; Seman et al., 2003; Bellusci et al., 2005; LIU et al., 2006; ZHANG et al., 2006). Yet, there are also studies which have reported only little or no differentiation with respect to altitude (ARADHYA et al., 1993; OYAMA et al., 1993; GEHRING and DELPH, 1999). According to our previous field investigations in the Wolong Nature Reserve of China, the growth, spatial pattern and population structure of $H$. rhamnoides are closely related to altitudinal gradients, although the changes in these characteristics occur non-linearly along increasing altitudes. Therefore, studies on the level of genetic diversity and its partitioning among $H$. rhamnoides pop- 
ulations at varying altitudes in this region are of a prime interest. In fact, there is relatively little previous work conducted on the level or partitioning of variation across altitudinal ranges, although a lot of such research has been done in relation to geography (YAO and Tigerstedt, 1993; BARTish et al., 1999; CHEN et al., 2004; TiAN et al., 2004a, b; WANG et al., 2005; LU et al., 2006).

In the present study, five natural populations of $H$. rhamnoides (each population consisting of a female and male subpopulation) occurring at altitudes ranging from 1,800 to $3,400 \mathrm{~m}$ above sea level in the Wolong Natural Reserve were chosen for the investigation to reveal the level and pattern of genetic variability. In addition, the possibility of genetic differentiation present between the female and male subpopulations of $H$. rhamnoides was also examined.

\section{Materials and Methods}

\subsection{Plant material}

During growing season 2004, 145 adult individuals of $H$. rhamnoides were collected from five different altitudes in the Wolong Natural Reserve of southwestern China $\left(30^{\circ} 45^{\prime} \sim 31^{\circ} 25^{\prime} \mathrm{N}, 102^{\circ} 25^{\prime} \sim 103^{\circ} 24^{\prime}\right.$ E). Sampling locations were selected along a vertical transect that spanned approximately 1,600 m over a linear distance of about $50 \mathrm{~km}$. Each sampling interval was about $400 \mathrm{~m}$. The altitudinal populations 1-5, i.e. P1800, P2200, P2600, P3000 and P3400, correspond to the altitudes $1,800,2,200,2,600,3,000$ and $3,400 \mathrm{~m}$, respectively. Each altitudinal population is comprised of a female subpopulation and a male subpopulation, i.e. $1800 \mathrm{~F}$, $1800 \mathrm{M}, 2200 \mathrm{~F}, 2200 \mathrm{M}, 2600 \mathrm{~F}, 2600 \mathrm{M}, 3000 \mathrm{~F}, 3000 \mathrm{M}$, $3400 \mathrm{~F}$ and $3400 \mathrm{M}$. In every population, twenty-five to thirty individuals were randomly sampled among adult individuals, each same-sex individual being separated by a distance of at least $50 \mathrm{~m}$. Each population sample included 15 females and 15 males, except for P3400 which was composed of 10 female and 15 male individuals. For molecular analyses, fresh leaves from each plant were collected, then frozen quickly and stored at $-80^{\circ} \mathrm{C}$ until DNA extraction.

\subsection{DNA extraction}

DNA was extracted from $0.5 \mathrm{~g}$ of fresh leaves following the protocol of CASTIGLIONE et al. (1993) with $1 \% \beta$-mercaptoethanol (v/v) and 1\% PVP $40000(\mathrm{w} / \mathrm{v})$ added to the CTAB extraction buffer. DNA concentrations were determined by comparison with a serial dilution of standard lambda DNA, and the quality of DNA was checked by a DNA-Protein instrument (Bio-RAD).

\subsection{PCR amplification}

The amplification of the ISSR markers was based on a modified protocol as described by YIN et al. (2002). All amplification reactions were performed in a GeneAmp ${ }^{\circledR}$ PCR System 9700 (Perkin Elmer Corp., Norwalk, CT, USA). Based on the clarity and reproducibility of the band patterns, fifteen primers (Table 1) out of the 45 primers (produced by the Biotechnology Laboratory,
University of British Columbia) first tested were selected for further use. The PCRs were performed in a volume of $25 \mu$ l containing $2.5 \mu$ l of the $10 \times$ reaction buffer (TaKaRa, Dalian), $200 \mu \mathrm{M}$ dNTP (Promega), $0.25 \mu \mathrm{M}$ primer, 1.0 U Taq polymerase (TaKaRa, Dalian) and 40-50 ng of genomic DNA. For each primer, amplifications were carried out in 96-well plates using the following program: an initial step of $5 \mathrm{~min}$ at $95^{\circ} \mathrm{C}$, followed by 40 cycles of $1 \mathrm{~min}$ at $95^{\circ} \mathrm{C}, 1 \mathrm{~min}$ at $53-60^{\circ} \mathrm{C}$, and 2 min at $72^{\circ} \mathrm{C}$, and a final extension step of 10 min at $72{ }^{\circ} \mathrm{C}$. The PCR products were separated on $1.8 \%$ agarose gels and stained with $0.1 \%$ ethidium bromide. The molecular weights were estimated using the GeneRuler $^{\mathrm{TM}} 100$ bp DNA Ladder Plus (Fermentas). The gel images were recorded and the band sizes were quantified using a Gel Doc 2000 system (Bio-RAD).

\subsection{Data analysis}

Only bands that were unambiguously scored across all samples were taken into consideration in the further analysis. The fragments amplified by ISSR primers were scored for each individual as present (1) or absent (0) on the basis of size comparison with external standards (GeneRuler ${ }^{\mathrm{TM}}$ 100bp DNA Ladder Plus). The following parameters were generated using the program POPGENE 1.31 to describe genetic variation at intraand inter-population or subpopulation level: Nei's gene diversity ( $h$ ), Shannon's information index $(i)$, the observed number of alleles $\left(N_{\mathrm{a}}\right)$ and the effective number of alleles $\left(N_{\mathrm{e}}\right)$ (LEWONTIN, 1972; NEI, 1973; YEH et al., 1997). Genetic divergence between populations or subpopulations was investigated using Nei's unbiased genetic distances (GD) and genetic identities (GID) (NEI, 1978). Nei's unbiased genetic distances were used to construct dendrograms using UPGMA (unweighted pairgroup arithmetic mean-method) for the mixed populations (including both sexes) (NEI, 1978). The genetic structure was further investigated using Nei's gene diversity statistics, including the total genetic diversity $\left(H_{\mathrm{T}}\right)$, genetic diversity within populations $\left(H_{\mathrm{S}}\right)$, and the relative magnitude of genetic differentiation among populations $\left(G_{\mathrm{ST}}=\left(H_{\mathrm{T}}-H_{\mathrm{S}}\right) / H_{\mathrm{T}}\right)(\mathrm{NEI}, 1973)$. An estimate of gene flow among populations $(\mathrm{Nm})$ was computed using the formula of $N \mathrm{~m}=\left(1-G_{\mathrm{ST}}\right) / 2 G_{\mathrm{ST}}$ (MCDERMOTT and MCDONALD, 1993).

Using the program GenAlEx version 6 (PEAKALL and Smouse, 2006), Mantel tests (MANTEL, 1967) were conducted to investigate the possible relationship between the genetic and geographical distances. This analysis tested isolation by distance based on the linear regression of pairwise genetic distance matrix against the geographic distance matrix between populations and subpopulations. To obtain an additional representation of genetic relationships among populations, a principal coordinate analysis (PCO), using the program GenAlEx version 6 , was conducted.

\section{Results}

\subsection{ISSR profiles}

A total of 326 markers generated by fifteen primers were scored, with sizes ranging between 400 and 1500 
Table 1. - The nucleotide sequences and annealing temperatures of the fifteen selected ISSR primers, and the numbers of bands scored in H. rhamnoides.

\begin{tabular}{llll}
\hline Primer & Primer sequence $\left(5^{\prime}-3^{\prime}\right)$ & Annealing temp. $\left({ }^{\circ} \mathrm{C}\right)$ & Number of bands recorded \\
IP-1 & $(\mathrm{GA})_{8} \mathrm{C}$ & 53 & 16 \\
IP-2 & $(\mathrm{AC})_{8} \mathrm{CTG}$ & 53 & 19 \\
IP-4 & $(\mathrm{GA})_{8} \mathrm{CTT}$ & 54 & 24 \\
807 & $(\mathrm{AG})_{8} \mathrm{~T}$ & 55 & 20 \\
808 & $(\mathrm{AG})_{8} \mathrm{C}$ & 53 & 20 \\
809 & $(\mathrm{AG})_{8} \mathrm{G}$ & 57 & 35 \\
826 & $(\mathrm{AC})_{8} \mathrm{C}$ & 53 & 25 \\
834 & $(\mathrm{AG})_{8} \mathrm{YT}$ & 51 & 22 \\
836 & $(\mathrm{AG})_{8} \mathrm{YA}$ & 49 & 20 \\
ISSR-32 & $(\mathrm{AG})_{8} \mathrm{AC}$ & 58 & 19 \\
ISSR-44 & $(\mathrm{AC})_{8} \mathrm{GA}$ & 53 & 21 \\
ISSR-47 & $(\mathrm{AC})_{8} \mathrm{GT}$ & 58 & 19 \\
ISSR-62 & $(\mathrm{AG})_{8} \mathrm{CA}$ & 54 & 22 \\
ISSR-64 & $(\mathrm{AG})_{8} \mathrm{CG}$ & 59 & 27 \\
ISSR-65 & $(\mathrm{AG})_{8} \mathrm{CC}$ & 60 & 17 \\
\hline
\end{tabular}

$\mathrm{Y}=\mathrm{C}$ or $\mathrm{T}$.

Table 2. - Genetic variability parameters of $H$. rhamnoides populations based on ISSRs.

\begin{tabular}{llllll}
\hline Population & $N_{\mathrm{a}}$ & $N_{\mathrm{e}}$ & $h$ & $i$ & $P(\%)$ \\
\hline P1800 & 1.752 & 1.384 & 0.233 & 0.358 & 75.2 \\
P2200 & 1.856 & 1.428 & 0.265 & 0.409 & 85.6 \\
P2600 & 1.810 & 1.432 & 0.259 & 0.395 & 81.0 \\
P3000 & 1.776 & 1.402 & 0.242 & 0.370 & 77.6 \\
P3400 & 1.755 & 1.408 & 0.247 & 0.375 & 75.5 \\
\hline
\end{tabular}

$N_{\mathrm{a}}$, observed number of alleles; $N_{\mathrm{e}}$, effective number of alleles; $h$, Nei's gene diversity; $i$, Shannon's indices; $P$, percentage of polymorphic loci.

bp. The number of scored markers per primer ranged from 16 (IP-1) to 35 (809) (Table 1), with an average of 21.7 markers per primer. At the population level, 324 markers were found polymorphic, with the percentage of polymorphic loci equaling $99.4 \%$. At the subpopulation level, 318 markers $(97.6 \%)$ were polymorphic among the five female subpopulations, while 322 markers $(98.8 \%)$ were polymorphic across the five male subpopulations.

\subsection{Intra-population and intra-subpopulation variation}

In individual populations, the percentages of polymorphic loci $(P)$ ranged from $75.2 \%$ to $85.6 \%$, with an average of $79.0 \%$ (Table 2). Nei's gene diversities $(h)$ varied from 0.233 to 0.265 , with an average of 0.249 , and Shannon's indices $(i)$ ranged from 0.358 to 0.409 , with an average of 0.381 . A similar trend was found in the values of the parameters $h$ and $i$. The mean observed number of alleles $\left(N_{\mathrm{a}}\right)$ ranged from 1.752 to 1.856 , while the mean effective number of alleles $\left(N_{\mathrm{e}}\right)$ varied from 1.384 to 1.432 . When calculated across populations, the $h$ and $i$ values equaled 0.305 and 0.468 , respectively, and the $N_{\mathrm{a}}$ and $N_{\mathrm{e}}$ values equaled 1.994 and 1.505, respectively. Among the five populations investigated, P2200 exhibited the highest level of variability while P1800 possessed the lowest value of variability (Figure 1).

In individual subpopulations, the percentages of polymorphic loci $(P)$ of each female and male subpopulation ranged from $66.6 \%$ to $81.9 \%$, and from $67.2 \%$ to $79.1 \%$, with an average of $72.6 \%$ and $72.0 \%$, respectively (Table 3 ). Nei's gene diversities $(h)$ of female and male subpopulations varied from 0.217 to 0.255 , and from 0.212 to 0.253 , with an average of 0.233 and 0.231 , and Shannon's indices $(i)$ ranged from 0.331 to 0.392 , and from 0.323 to 0.384 , with an average of 0.355 and 0.351 , respectively. The mean observed number of alleles $\left(N_{\mathrm{a}}\right)$ ranged from 1.666 to 1.819 , and from 1.672 to 1.791 ,

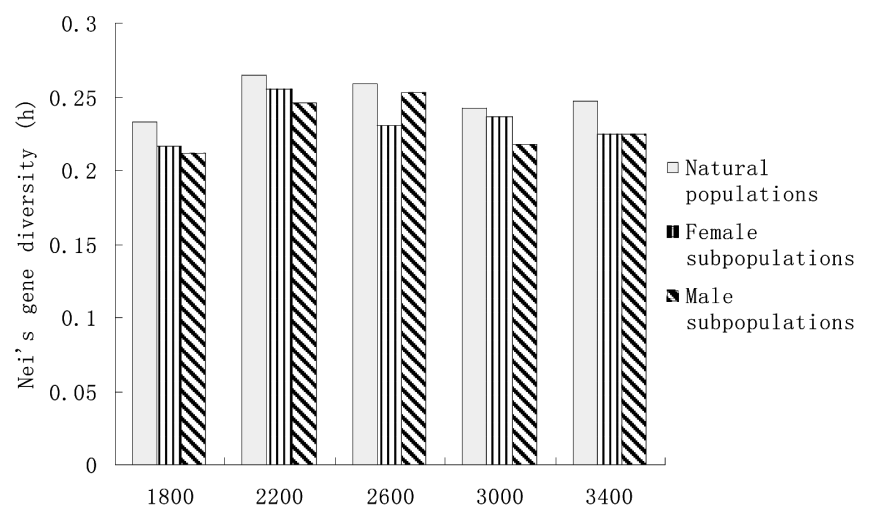

Figure 1. - Comparison of Nei's (1978) gene diversity among the natural populations, and among the male and female subpopulations of $H$. rhamnoides originating from the Wolong Natural Reserve. 
Table 3. - Genetic variability parameters of H. rhamnoides in female and male subpopulations based on ISSRs.

\begin{tabular}{llllll}
\hline Subpopulation & $N_{\mathrm{a}}$ & $N_{\mathrm{e}}$ & $h$ & $i$ & $P(\%)$ \\
\hline $1800 \mathrm{~F}$ & 1.687 & 1.359 & 0.217 & 0.331 & 68.7 \\
$2200 \mathrm{~F}$ & 1.819 & 1.414 & 0.255 & 0.392 & 81.9 \\
$2600 \mathrm{~F}$ & 1.733 & 1.386 & 0.231 & 0.351 & 73.3 \\
$3000 \mathrm{~F}$ & 1.727 & 1.393 & 0.237 & 0.360 & 72.7 \\
$3400 \mathrm{~F}$ & 1.666 & 1.382 & 0.225 & 0.339 & 66.6 \\
$1800 \mathrm{M}$ & 1.672 & 1.357 & 0.212 & 0.323 & 67.2 \\
$2200 \mathrm{M}$ & 1.791 & 1.407 & 0.246 & 0.378 & 79.1 \\
$2600 \mathrm{M}$ & 1.776 & 1.424 & 0.253 & 0.384 & 77.6 \\
$3000 \mathrm{M}$ & 1.678 & 1.366 & 0.218 & 0.331 & 67.8 \\
$3400 \mathrm{M}$ & 1.681 & 1.377 & 0.225 & 0.340 & 68.1 \\
\hline
\end{tabular}

$N_{\mathrm{a}}$, observed number of alleles; $N_{\mathrm{e}}$, effective number of alleles; $h$, Nei's gene diversity; $i$, Shannon's indices; $P$, percentage of polymorphic loci.

while the mean effective number of alleles $\left(N_{\mathrm{e}}\right)$ varied from 1.359 to 1.414 , and from 1.357 to 1.424 in female and male subpopulations, respectively. When calculated across female and male subpopulations, the $h$ and $i$ values equaled 0.300 and 0.459 , and 0.303 and 0.465 , respectively, while the $N_{\mathrm{a}}$ and $N_{\mathrm{e}}$ values equaled 1.976 and 1.499, and 1.988 and 1.499, respectively. Among the five female subpopulations investigated, $2200 \mathrm{~F}$ exhibited the highest level of variability while $1800 \mathrm{~F}$ possessed the lowest value of variability (Figure 1). However, among the five male subpopulations, 2600M exhibited the highest level of variability and $2200 \mathrm{M}$ almost as much variation, while $1800 \mathrm{M}$ possessed the lowest value of variability.

\subsection{Inter-population and inter-subpopulation differentia- tion}

The total gene diversity $\left(H_{\mathrm{T}}\right)$ and gene diversity within populations $(H \mathrm{~s})$ revealed by ISSR analyses in the mixed populations of $H$. rhamnoides equaled 0.305 and 0.249 , respectively. The coefficient of genetic differentiation $\left(G_{\mathrm{ST}}\right)$, equaling 0.182 , showed the presence of some degree of genetic differentiation among mixed populations. The level of gene flow $(\mathrm{Nm}$, the number of migrating individuals among populations per generation) was estimated to equal 2.249.
When restricting the analysis to the five female and male subpopulations, the total gene diversity $\left(H_{\mathrm{T}}\right)$ and gene diversity within populations $(H \mathrm{~s})$ were 0.299 and 0.233 , and 0.303 and 0.231 , respectively. The coefficient of genetic differentiation $\left(G_{\mathrm{ST}}\right)$, equaling 0.222 and 0.238 , respectively, showed considerable genetic differentiation among female and male subpopulations. The level of gene flow $(\mathrm{Nm})$ was estimated to be 1.758 and 1.605 , respectively. The analysis of molecular variance (AMOVA) taking into account the female and male subpopulations showed that $22.2 \%$ of the total variation was maintained among populations, and only $3.8 \%$ of the variability resided between female and male subpopulations.

\subsection{Genetic relationships among populations and sub- populations}

Nei's unbiased genetic distances were calculated for populations and subpopulations to estimate their divergence (Tables 4). The mean distance among the five mixed populations equaled 0.0973 (pairwise range 0.0528-0.1600). The lowest genetic distance was found between P3000 and P3400, while the greatest distance was detected between P1800 and P3000. The mean distance among the five female subpopulations equaled 0.1150 (pairwise range $0.0590-0.1796$ ) (Table 4). The

Table 4. - Nei's genetic distances and genetic identities between female and male subpopulations of H. rhamnoides.

\begin{tabular}{lllllllllll}
\hline Subp. & $1800 \mathrm{~F}$ & $2200 \mathrm{~F}$ & $2600 \mathrm{~F}$ & $3000 \mathrm{~F}$ & $3400 \mathrm{~F}$ & $1800 \mathrm{M}$ & $2200 \mathrm{M}$ & $2600 \mathrm{M}$ & $3000 \mathrm{M}$ & $3400 \mathrm{M}$ \\
\hline $1800 \mathrm{~F}$ & - & 0.9079 & 0.8356 & 0.8390 & 0.8409 & 0.9684 & 0.8691 & 0.8397 & 0.8323 & 0.8359 \\
$2200 \mathrm{~F}$ & 0.0966 & - & 0.9096 & 0.9108 & 0.9052 & 0.8866 & 0.9632 & 0.9115 & 0.9063 & 0.8967 \\
$2600 \mathrm{~F}$ & 0.1796 & 0.0948 & - & 0.9169 & 0.9142 & 0.8286 & 0.9185 & 0.9647 & 0.9153 & 0.9038 \\
$3000 \mathrm{~F}$ & 0.1755 & 0.0935 & 0.0868 & - & 0.9428 & 0.8289 & 0.9221 & 0.9275 & 0.9715 & 0.9210 \\
$3400 \mathrm{~F}$ & 0.1733 & 0.0996 & 0.0897 & 0.0590 & - & 0.8309 & 0.9141 & 0.9147 & 0.9366 & 0.9596 \\
$1800 \mathrm{M}$ & 0.0322 & 0.1203 & 0.1880 & 0.1876 & 0.1852 & - & 0.8468 & 0.8319 & 0.8177 & 0.8278 \\
$2200 \mathrm{M}$ & 0.1403 & 0.0375 & 0.0851 & 0.0811 & 0.0898 & 0.1663 & - & 0.9268 & 0.9183 & 0.9143 \\
$2600 \mathrm{M}$ & 0.1747 & 0.0927 & 0.0359 & 0.0752 & 0.0892 & 0.1840 & 0.0760 & - & 0.9222 & 0.9060 \\
$3000 \mathrm{M}$ & 0.1835 & 0.0984 & 0.0885 & 0.0289 & 0.0655 & 0.2013 & 0.0853 & 0.0810 & - & 0.9242 \\
$3400 \mathrm{M}$ & 0.1792 & 0.1090 & 0.1011 & 0.0823 & 0.0412 & 0.1890 & 0.0896 & 0.0987 & 0.0788 & - \\
\hline
\end{tabular}

Above diagonal: genetic identities; below diagonal: genetic distances. 
smallest genetic distance was found between subpopulations $3000 \mathrm{~F}$ and $3400 \mathrm{~F}$, while the greatest distance occurred between subpopulations $1800 \mathrm{~F}$ and $2600 \mathrm{~F}$. On the other hand, the genetic distances among the five male subpopulations varied from 0.0760 (subpopulations $2200 \mathrm{M}$ and $2600 \mathrm{M}$ ) to 0.2013 , (subpopulations $1800 \mathrm{M}$ and $3000 \mathrm{M}$ ) with a mean value of 0.1250 (Table 4).

To investigate the presence of a possible association between the genetic and vertical distances among populations and subpopulations, we compared these two matrices with a Mantel test. A significantly positive correlation was found between the two types of distances for the five mixed populations $(R=0.636, p=0.037)$ and for the five female subpopulations $(R=0.710, p=0.027)$ (Figure 2), while the corresponding relationship among the male subpopulations was not significant $(R=0.505$, $\mathrm{p}=0.062)$ (Figure 2).

\subsection{Cluster analyses}

A UPGMA analysis was conducted on the basis of Nei's (1978) genetic distances for mixed populations,

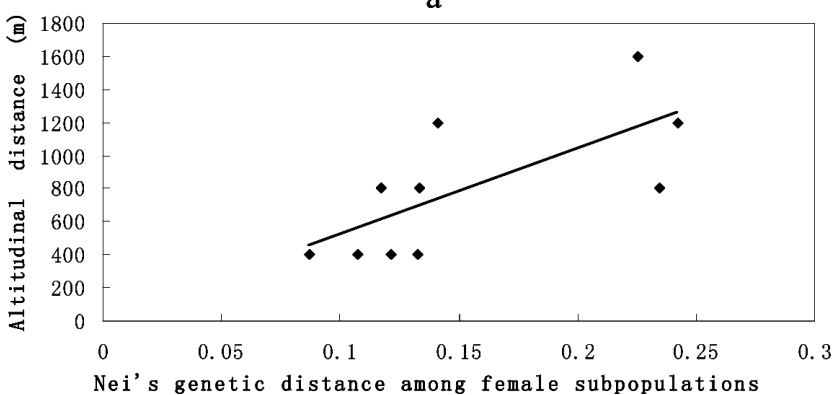

百
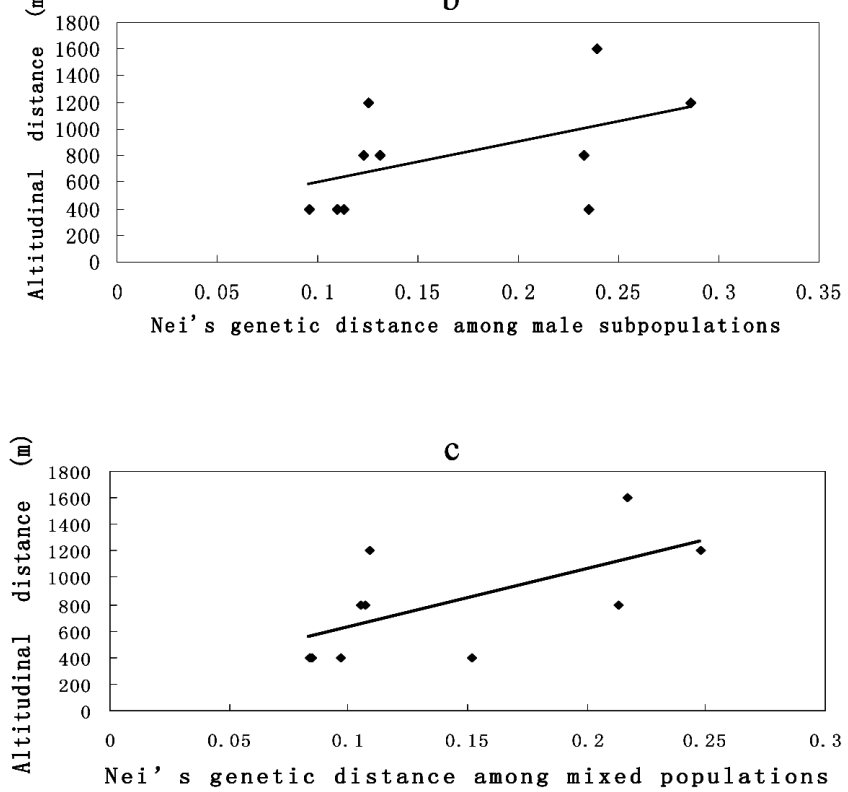

Figure 2. - Mantel tests for the relationship between genetic and altitudinal distances in the female $(\mathrm{R}=0.710, \mathrm{p}=0.027)$ (a) and male $(\mathrm{R}=0.505, \mathrm{p}=0.062)$ (b) subpopulations, and in the mixed populations $(\mathrm{R}=0.636, \mathrm{p}=0.037$ ) (c) of $H$. rhamnoides originating from the Wolong Natural Reserve. female subpopulations and male subpopulations. Except for the dendrogram based on the female subpopulations, the dendrograms consisted of three clusters, the first one with low-elevation population or subpopulation P1800 or $1800 \mathrm{M}$, the second one with mid-elevation populations or subpopulations P2200 and P2600, or 2200M and $2600 \mathrm{M}$, and the third one with high-elevation populations or subpopulations P3000 and P3400, or 3000M and $3400 \mathrm{M}$. The dendrogram based on female subpopulations displayed a slightly different trend. It showed that subpopulations $3000 \mathrm{~F}$ and $3400 \mathrm{~F}$ first formed a cluster, and then subpopulations 2600F, 2200F and $1800 \mathrm{~F}$ were clustered with that one by one. When all subpopulations were included in the cluster analyses, the dendrogram showed a similar trend as detected in the dendrograms based on mixed populations or male subpopulations (Figure 3). Its specific character is that subpopulations of the same altitude, e.g. $1800 \mathrm{~F}$ and $1800 \mathrm{M}$, firstly formed a cluster.

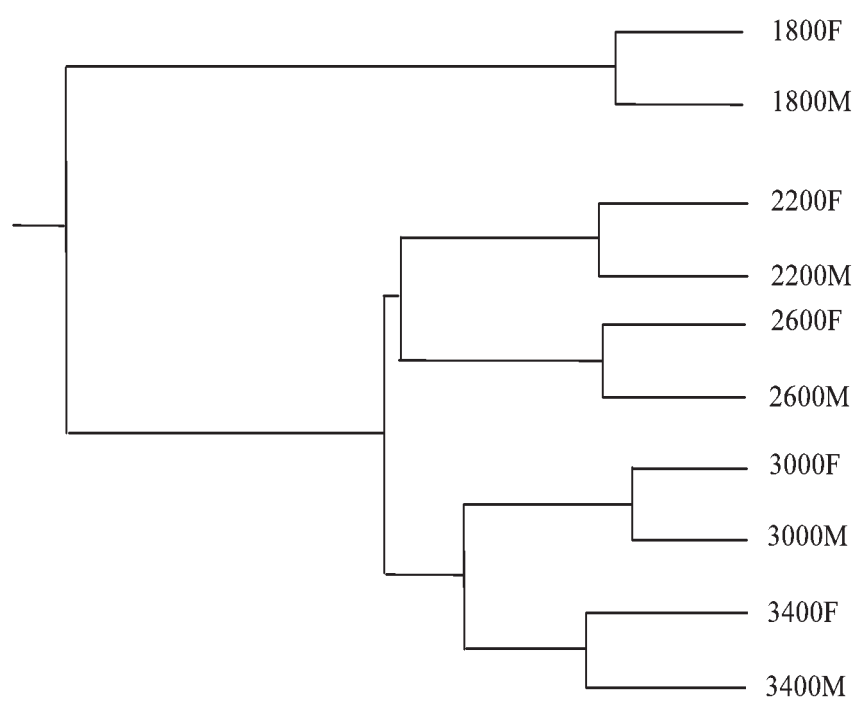

Figure 3. - Dendrogram for all subpopulations of $H$. rhamnoides originating from the Wolong Natural Reserve. Calculations were performed using the unweighted pair-group arithmetic mean-method for the genetic distance values given in Table 4.

\subsection{Principal coordinate analysis}

A PCO analysis was performed to provide spatial representation of the relative genetic distances among individuals and to determine the consistency of differentiation among populations defined by the cluster analysis (Figure 4). The first three principal coordinate axes obtained in the analysis of mixed populations accounted for $43.2 \%, 14.8 \%$ and $12.7 \%$ of the total variation, respectively (cumulative value $=70.7 \%$ ). In an agreement with the cluster analysis, individuals from each population formed a separate plot and could be clearly distinguished from individuals originating from other populations. Population P1800 expressed the highest level of genetic differentiation in relation to other populations, while population P2200 formed two looser subclusters of individuals and less population-specific identity. 


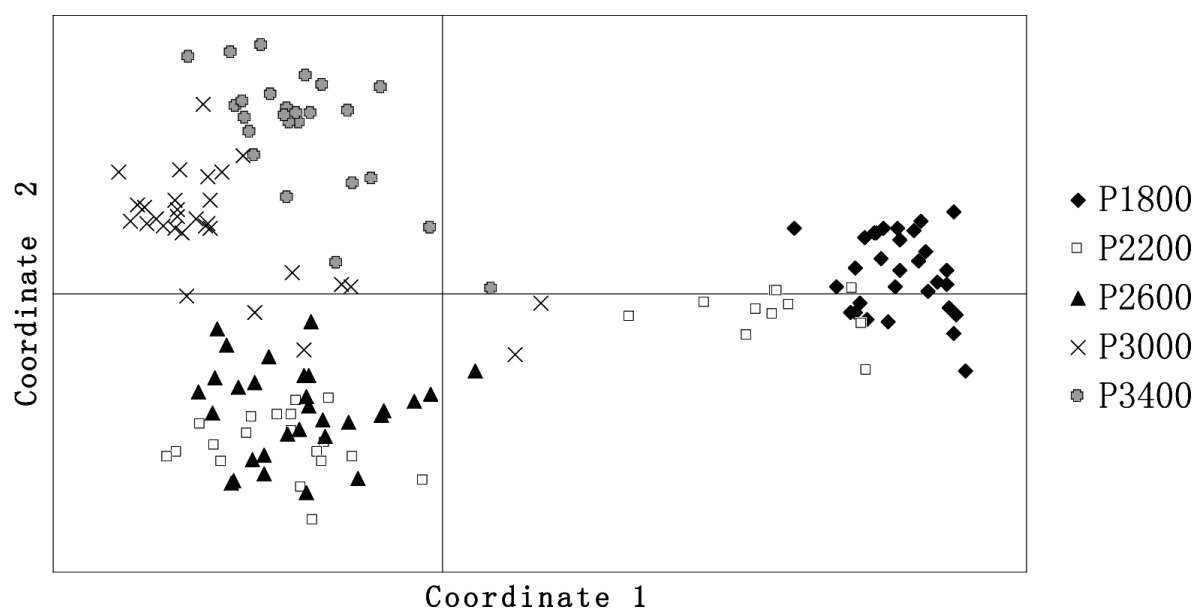

Figure 4. - PCO analysis for the populations of H. rhamnoides originating from different altitudes from the Wolong Natural Reserve.

\section{Discussion}

The ISSR analysis conducted for the $H$. rhamnoides populations located in the Wolong Natural Reserve of China revealed the presence of high levels of genetic variation (as measured by mean $h=0.249$ and $H_{\mathrm{T}}=$ 0.305). This is an expected result for a woody, moderately long-lived, outcrossing and wind-pollinated species (HAMRICK et al., 1992). The degree of diversity was higher than the values previously reported for $H$. rhamnoides and other subspecies belonging to $H$. rhamnoides (BARTISH et al., 1999, 2000; RUAN et al., 2004; TIAN et al., 2004a, b).

Furthermore, the genetic diversity of $H$. rhamnoides was found to vary significantly with changing elevation, showing a trend that mid-elevation populations $(2,200 \mathrm{~m}$ and $2,600 \mathrm{~m}$ ) were genetically more diverse than both low-elevation $(1,800 \mathrm{~m})$ and high-elevation populations $(3,000 \mathrm{~m}$ and $3,400 \mathrm{~m}) . H$. rhamnoides is thought to be stressed by drought and high temperature at low elevations, and by low temperature at high elevations (Li $e t$ al., 2007). Unfavourable environments at both low and high altitudinal zones may lead to an increase in vegetative reproduction and to a decrease in resource-demanding sexuality, which may result in a loss of genetic variation. In addition, from a geographical point of view, the low- and high-elevation populations can be considered as being marginal and isolated. Lower levels of genetic diversity in low-elevation populations may also be ascribed to the negative effects of anthropogenic pressures, such as road building and other human activity, which gradually disrupt the habitats of $H$. rhamnoides and result in reduced population density and size, and habitat fragmentation. The presence of lower genetic diversity in high-elevation populations is likely affected by decreased sexual reproduction imposed by pollination limitation and shortened flowering season (Young et al., 2002). Natural selection in harsh environments may also lead to a loss in genetic variability. On the other hand, the mid-elevation populations of $H$. rhamnoides are thought to be free from both drought and high- and low-temperature stresses. The evidence that there exists an optimum zone for $H$. rhamnoides in the Wolong Natural Reserve has been documented by Li et al.
(2007). The high genetic variability present in the midelevation populations of $H$. rhamnoides is assumed to be related to larger population sizes in the mid-altitudinal zone, where favorable ecological conditions permit a continuous distribution covering the zone from $2,200 \mathrm{~m}$ to $2,600 \mathrm{~m}$ above sea level. In general, genetic diversity is known to be positively correlated with population size (FRANKHAM, 1996).

The analysis restricted to female subpopulations and male subpopulations demonstrated the following: (1) In both sexes, the peak value of genetic variation consistently appears in mid-elevation subpopulations; (2) with the exception of the altitude $2,600 \mathrm{~m}$, the genetic variability of female subpopulations is slightly higher than that of male subpopulations. Although only few previous reports are available with respect to sex-specific genetic differentiation in dioecious plant species, sex-related differences in morphological and physiological characteristics have been studied extensively (KRISCHIK and DENNO, 1990; Gehring and Monson, 1994; Jones et al., 1999; WANG and GRIFFIN, 2003; LI et al., 2004, 2005). Most of these studies confirm the finding that males are often impacted less than females when both sexes grow in the same stressful environment, or that males are more adaptive than females in a variety of ways when the sexes are compared in stressful environments. A higher frequency of vegetative reproduction in the males of H. rhamnoides may account for a partial loss of genetic diversity in males when compared to females at altitudes other than $2,600 \mathrm{~m}$. The sex-specific diversity values peaking at $2,200 \mathrm{~m}$ in females and at $2,600 \mathrm{~m}$ in males may reflect the presence of sex-specific selection or differences in altitude optimums or in the prevalence of sexual reproduction.

The genetic structure of $H$. rhamnoides followed the general pattern detected in woody species with widespread distributions and outcrossing mating systems. Such plants possess more genetic diversity within populations and less variation among populations than do species with other combinations of traits (HAMRICK and GODT, 1989). In general, population differentiation is expected to be very restricted in long-lived woody, outcrossed, dioecious and wind-pollinated species (LOVELESS 
and HAMRICK, 1984; HAMRICK and GODT, 1989, 1996; BARTISH et al., 1999). Yet, the level of genetic differentiation, recorded in the present study for $H$. rhamnoides $\left(G_{\mathrm{ST}}=0.182\right)$ within a geographically restricted area using ISSR markers, is quite high. Lower levels of differentiation have been detected in previous studies on $H$. rhamnoides based on isozyme, RAPD and ISSR analyses (YAO and Tigerstedt, 1993; BARTish et al., 1999, 2000; BARTISH, 2000; RUAN et al., 2004; TIAN et al., $2004 \mathrm{a}, \mathrm{b})$. The relatively high genetic differentiation detected here can be mainly ascribed to the following two causes: 1) The sampling sites located in the Wolong Natural Reserve are separated by tall, zigzag positioned mountains, and, consequently, the gene flow among populations is limited. 2) A further reason can be the floral asynchrony at different altitudes (REISCH et al., 2005). An increase in altitude causes a decrease in temperature and, further, it postpones the flower development. Generally, flowering is delayed by 2-3 days for every $200 \mathrm{~m}$ of elevation in the Wolong Natural Reserve. Therefore, the flowering periods do not overlap in populations or subpopulations with altitude differences greater than $500 \mathrm{~m}$. It follows that the phenological gap also contributes to the observed differentiation.

In the present study, Mantel tests showed positive correlations between altitudinal distances and genetic distances among populations or subpopulations. The observed relationship between altitude and genetic distances, and the result of the cluster analysis including populations or male subpopulations that classified the groups into three altitude clusters suggest that altitude is a major factor that restricts gene flow between populations and subpopulations. A comparable situation has been reported in Psathyrostachys huashanica by WANG et al. (2006). In addition, a cluster analysis grouping the same altitude females and males into the same clusters shows that female and male subpopulations of the same elevations are genetically alike. The analysis of molecular variance showed that only $3.8 \%$ of the variability resided between female and male subpopulations. Such a very restricted proportion of the total molecular variance between females and males is due to common sexuality and the mixing of genetic material between the sexes.

\section{Acknowledgements}

The research was supported by the Outstanding Young Scientist Program of the National Natural Science Foundation of China (No. 30525036) and the China National Key Program of the International Cooperation for Science and Technology (No. 2005DFA30620).

\section{References}

Aradhya, K. M., D. Mueller-Dombois and T. A. RankeR (1993): Genetic structure and differentiation in Metrosideros polymorpha (Myrtaceae) along altitudinal gradients in Maui, Hawaii. Genet. Res. 61: 159-170.

BARTISH, G. I. (2000): Assessment of genetic diversity using RAPD analysis in a germplasm collection of sea buckthorn. Agric. Food Sci. in Finland 9: 279-289.
BARTish, I. V., N. JePPSSON and H. NyBOM (1999): Population genetic structure in the dioecious pioneer plant species Hippophae rhamnoides investigated by random amplified polymorphic DNA (RAPD) markers. Mol. Ecol. 8: 791-802.

Bartish, I. V., N. Jeppsson, G. I. Bartish, R. Lu and H. Nувом (2000): Inter- and intraspecific genetic variation in Hippophae (Elaeagnaceae) investigated by RAPD markers. Plant Syst. Evol. 225: 85-101.

Bellusci, F., G. Pellegrino, A. M. Palermo, D. Gargano and A. Musacchio (2005): Genetic differentiation of the endemic orophyte Campanula pollinensis along an altitudinal gradient. Plant Biosyst. 139: 349-356.

CAMACho, F. J. and A. Liston (2001): Population structure and genetic diversity of Botrychium pumicola (Ophioglossaceae) based on inter-simple sequence repeats (ISSR). Am. J. Bot. 88: 1065-1070.

Castiglione, S., G. Wang, G. Damiani, C. Bandi, S. Bisoffi and F. SALA (1993): RAPD fingerprints for identification and for taxonomic studies of elite poplar (Populus spp) clones. Theor. Appl. Genet. 87: 54-59.

Chen, Y., B. Hu, F. Xu, W. Zhang, H. Zhou and L. QU (2004): Genetic variation of Cordyceps sinensis, a fruitbody-producing entomopathogenic species from different geographical regions in China. FEMS Microbiol. Lett. 230: 153-158.

Ettl, G. J. and D. L. Peterson (2001): Genetic variation of Subalpine fir (Abies lasiocarpa (Hook.) NUTT.) in the Olympic Mountains, WA, USA. Silvae Genet. 50: 3-4.

Fahima, T., G. L. Sun, A. Beharav, T. Krugman, A. Beiles and E. NEvo (1999): RAPD polymorphism of wild emmer wheat populations, Triticum dicoccoides, in Israel. Theor. Appl. Genet. 98: 434-447.

FRANKHAM, R. (1996): Relationship of genetic variation to population size in wildlife. Conserv. Biol. 10: 1500-1508.

GeHRING, J. L. and R. K. Monson (1994): Sexual differences in gas exchange and response to environmental stress in dioecious Silene latifolia (Caryophyllaceae). Am. J. Bot. 81: 166-174.

GEHRING, J. L. and L. F. DELPH (1999): Fine-scale genetic structure and clinal variation in Silene acaulis despite high gene flow. Heredity 82: 628-637.

HAMRICK, J. L. and M. J. W. GODT (1989): Isozymes and the analysis of genetic structure in plant populations. In: Isozymes in Plant Biology (Soltis, D. E. and Soltis P. S. eds.), Discorides Press, Portland, OR, pp. 87-105.

HAMRICK, J. L. and M. J. W. GoDT (1996): Effects of life history traits on genetic diversity in plant species. Philos. T. Roy. Soc. B. 351: 1291-1298.

Hamrick, J. L., M. J. W. Godt and S. L. Sherman-Broyles (1992) Factors influencing levels of genetic variation in woody plant species. New For. 6: 95-124.

Jones, M. H., S. E. Macdonald and G. H. R. HenRY (1999): Sex- and habitat-specific responses of a high arctic willow, Salix arctica, to experimental climate change. Oikos 87: 129-138.

KRISCHIK, V. A. and R. F. Denno (1990): Patterns of growth, reproduction, defense, and herbivory in the dioecious shrub, Baccharis halimifolia (Compositae). Oecologia 83: 182-190.

LEWONTIN, R. C. (1972): The apportionment of human diversity. Evol. Biol. 6: 381-398.

Li, C., J. REN, J. LUO and R. LU (2004): Sex-specific physiological and growth responses to water stress in Hippophae rhamnoides L. populations. Acta Physiol. Plant. 26: $123-129$. 
Li, C., Y. YANG, O. JuntTila and E. T. PAlva (2005): Sexual differences in cold acclimation and freezing tolerance development in sea buckthorn (Hippophae rhamnoides L.) ecotypes. Plant Sci. 168: 1365-1370.

Li, C., G. XU, R. ZANG, H. Korpelainen and F. Berninger (2007): Sex-related differences in leaf morphological and physiological responses in Hippophae rhamnoides along an altitudinal gradient. Tree Physiol. 27: 399-406.

Liu, Z., A. Zhao, X. Kang, S. Zhou and J. López-Pujol (2006): Genetic diversity, population structure, and conservation of Sophora moorcroftiana (Fabaceae), a shrub endemic to the Tibetan Plateau. Plant Biol. 8: 81-92.

LOVELESS, M. D. and J. L. HAMRICK (1984): Ecological determinants of genetic structure in plant populations. Annu. Rev. Ecol. Syst. 15: 65-95.

Lu, R. (1992) Sea buckthorn - A multipurpose plant species for fragile mountains. ICIMOD Occasional Paper No. 20. Kathmandu, Nepal, 26 p.

Lu, Z., Y. Wang, Y. Peng, H. Korpelainen and C. Li (2006): Genetic diversity of Populus cathayana Rehd populations in southwestern china revealed by ISSR markers. Plant Sci. 170: 407-412.

MANTEL, N. (1967): The detection of disease clustering and a generalized regression approach. Cancer Res. 27: 209-212.

McDermotT, J. M. and B. A. McDonAld (1993): Gene flow in plant pathosystems. Annu. Rev. Phytopathol. 31: 353-373.

Nan, P., S. Shi, S. Peng, C. Tian and Y. Zhong (2003): Genetic diversity in Primula obconica (Primulaceae) from central and south-west China as revealed by ISSR markers. Ann. Bot-London 91: 329-333.

NEI, M. (1973): Analysis of gene diversity in subdivided populations. Proc. Natl. Acad. Sci. 70: 3321-3323.

NEI, M. (1978): Estimation of average heterozygosity and genetic distance from a small number of individuals. Genetics 89: 583-590.

Nevo, E., A. Beiles and N. Storch (1983): Microgeographic edaphic differentiation in hordein polymorphisms of wild barley. Theor. Appl. Genet. 64: 123-132.

OYAMA, K., M. ITO, T. YAHARA and M. ONo (1993): Low genetic differentiation among populations of Arabis serrata (Brassicaceae) along an altitudinal gradient. J. Plant Res. 106: 143-148.

Peakall, R. and P. E. Smouse (2006): GenAlEx 6: genetic analysis in Excel. Population genetic software for teaching and research. Mol. Ecol. Notes 6: 288-295.

Persson, H. A. and H. NyBom (1998): Genetic sex determination and RAPD marker segregation in the dioecious species sea buckthorn (Hippophae rhamnoides L.). Hereditas 129: 45-51.

REHFELDT, G. E. (1994): Adaptation of Picea engelmannii populations to the heterogeneous environments of the Intermountain West. Can. J. Bot. 72: 1197-1208.

REISCH, C., A. ANKE and M. RÖHL (2005): Molecular variation within and between ten populations of Primula farinosa (Primulaceae) along an altitudinal gradient in the northern Alps. Basic Appl. Ecol. 6: 35-45.

RuAn, C. J., P. QIN, J. W. Zheng and Z. X. He (2004): Genetic relationships among some cultivars of sea buckthorn from China, Russia and Mongolia based on RAPD analysis. Sci. Hortic-Amsterdam 101: 417-426.
SÁenz-Romero, C. and B. L. TAPiA-Olivares (2003): Pinus oocarpa isoenzymatic variation along an altitudinal gradient in Michoacán, Mexico. Silvae Genet. 52: 237-240.

Sáenz-Romero, C., R. R. Guzmán-Reyna and G. E. REHFELDT (2006): Altitudinal genetic variation among Pinus oocarpa populations in Michoacán, Mexico Implications for seed zoning, conservation, tree breeding and global warming. For. Ecol. Manage. 229: 340-350.

Seman, K., A. BJoRnstad and B. Stedje (2003): Genetic diversity and differentiation in Ethiopian populations of Phytolacca dodecandra as revealed by AFLP and RAPD analyses. Genet. Resour. Crop Evol. 50: 649-661.

Tian, C. J., Y. D. LeI, S. H. ShI, P. NAN, J. K. Chen and Y. ZHONG (2004a): Genetic diversity of sea buckthorn (Hippophae rhamnoides) populations in northeastern and northwestern China as revealed by ISSR markers. New For. 27: 229-237.

Tian, C. J., P. NAN, S. H. Shi, J. K. Chen and Y. Zhong (2004b): Molecular genetic variation in Chinese populations of Three Subspecies of Hippophae rhamnoides. Biochem. Genet. 42: 259-267.

WANG, L., J. GUO and G. F. ZHAO (2006): Genetic diversity of the endangered and endemic species Psathyrostachys huashanica natural populations using simple sequence repeats (SSRs) markers. Biochem. Syst. Ecol. 34: 310-318.

WANG, X. and K. L. GRIFFIN (2003): Sex-specific physiological and growth responses to elevated atmospheric $\mathrm{CO}_{2}$ in Silene latifolia Poiret. Global Change Biol. 9: 612-618.

Wang, Y., J. Luo, X. Xue, H. Korpelainen and C. Li (2005): Diversity of microsatellite markers in the populations of Picea asperata originating from the mountains of China. Plant Sci. 168: 707-714.

WolfE, A. D. and A. Liston (1998): Contributions of PCRbased methods to plant systematics and evolutionary biology. In: Molecular Systematics of Plants: DNA Sequencing (Soltis, P. S., Soltis, D. E. and Doyle, J. J. eds.), Kluwer, New York, pp. 43-86.

WU, Z. Y. and P. H. RAVEN (1994): Flora of China. Vol. 4. Science Press and Missouri Botanical Garden, Beijing, China and St. Louis, USA, 287 p.

YAO, Y. and P. TIGERSTEDT (1993): Isozyme studies of genetic diversity and evolution in Hippophae. Genet. Resour. Crop Evol. 40: 153-164.

YeH, F. C., R. C. YANG and T. BoYle (1997): POPGENE, version 1.32 edition, Software Microsoft Window-Based Freeware for Population Genetic Analysis. University of Alberta, Edmonton, Alta.

Yin, T. M., X. Y. Zhang, M. R. Huang, M. X. Wang, Z. QIANG, S. TU, L. ZHU and R. WU (2002): Molecular linkage maps of the Populus genome. Genome 45: 541-555.

YounG, A. G., J. H. HiLl and B. G. MurRaY (2002): Breeding system, genetic diversity and clonal structure in the subalpine forb Rutidosis leiolepis F. Muell. (Asteraceae). Biol. Conserv. 106: 71-78.

Zhang, X., H. Korpelainen and C. Li (2006): Microsatellite variation of Quercus aquifolioides populations at varying altitudes in the Wolong Natural Reserve of China. Silva Fenn. 40: 407-415. 